\title{
Optimizing ixabepilone treatment schedules in patients with advanced or metastatic breast cancer
}

\author{
Nancy Egerton
}

Received: 17 May 2010 / Accepted: 9 September 2010 / Published online: 1 October 2010

(C) The Author(s) 2010. This article is published with open access at Springerlink.com

\begin{abstract}
The epothilone B analog, ixabepilone, demonstrates low susceptibility to drug resistance mechanisms and has demonstrated clinically meaningful efficacy in patients refractory to other chemotherapeutic options. Ixabepilone is approved by the FDA for treatment of patients with metastatic breast cancer (MBC) progressing after taxanes and anthracyclines, either in combination with capecitabine or as monotherapy if the patient has already progressed on capecitabine. Ixabepilone is generally well tolerated at the approved dose and administration schedule of $40 \mathrm{mg} / \mathrm{m}^{2}$ every 3 weeks. The most commonly observed dose-limiting adverse events (AEs) associated with ixabepilone are myelosuppression and peripheral neuropathy. Dose modification including dose reduction and dosing schedule modification may be utilized to manage toxicities, but this must be based on careful hematologic, neurologic, and liver function monitoring. Other ixabepilone dose schedules are being evaluated to further improve the risk/ benefit profile. Weekly and daily schedules of ixabepilone have shown useful efficacy and reasonable tolerability. A recent phase II trial compared the tolerability of ixabepilone dosed once weekly $\left(16 \mathrm{mg} / \mathrm{m}^{2}\right.$ on Days 1,8 , and 15 of each 28 -day cycle) or every 3 weeks $\left(40 \mathrm{mg} / \mathrm{m}^{2}\right.$ on Day 1 of each 21-day cycle) in patients with MBC. Preliminary data showed that both dosing schedules had an acceptable safety profile; however, more AEs were reported in patients receiving ixabepilone every 3 weeks. Ixabepilone is also being evaluated in combination with other anticancer agents (e.g., bevacizumab and lapatinib), in earlier breast cancer settings and in other indications.
\end{abstract}

\section{N. Egerton $(\bowtie)$}

Pharmacy Services, New York Oncology Hematology, 400 Patroon Creek Blvd, Ste 1, Albany, NY 12206, USA

e-mail: Nancy.Egerton@usoncology.com
Keywords Ixabepilone - Breast cancer - Metastatic · Advanced $\cdot$ Epothilones $\cdot$ Treatment schedules

\section{Introduction}

Epothilones are cytotoxic metabolites from the myxobacterium Sorangium cellulosum that stabilize microtubules. They induce cell death by apoptosis [1] via a mechanism that is similar to that of taxanes [2]. Ixabepilone, a novel semisynthetic analog of epothilone B [3], has been modified to retain cytotoxic activity while improving the stability and pharmacokinetic properties of the agent. Ixabepilone binds to a site similar to the taxane binding site on the $\beta$ subunit of the tubulin heterodimer, but in a qualitatively different manner than paclitaxel [4]. Ixabepilone is able to competitively inhibit paclitaxel binding [2,5].

Unlike taxanes, ixabepilone demonstrates low susceptibility to drug resistance mechanisms, including those associated with resistance to multiple drug classes (such as high expression of the drug efflux proteins P-glycoprotein and multidrug resistance protein) and those specifically associated with taxane resistance (such as high expression of BIIItubulin, an isotype of tubulin to which taxanes cannot bind) [6-8]. These features, coupled with the tubulin binding differences between epothilones and taxanes, may open the door for the treatment of taxane-resistant tumors [9].

Ixabepilone was approved by the FDA in October 2007 for treatment of patients with MBC progressing after taxanes and anthracyclines, either in combination with capecitabine, or as monotherapy if the patient has already progressed on capecitabine [10]. Given ixabepilone has been available for a number of years, we believe it useful to review the current approved dosing. This paper summarizes the supporting data for the current approved dosing schedule, 
as well as the other treatment schedules that have been investigated to optimize clinical efficacy and tolerability. In addition, situations for which the dose of ixabepilone may need to be altered and special administration considerations will be discussed.

\section{Ixabepilone monotherapy doses and schedules}

The approved dose of ixabepilone for treating metastatic breast cancer (MBC) is $40 \mathrm{mg} / \mathrm{m}^{2}$ infused over $3 \mathrm{~h}$ every 3 weeks [10]. The dose of ixabepilone is the same for monotherapy and for combination therapy with capecitabine. Ixabepilone is currently supplied as a lyophilized powder with a polyoxyethylated castor oil/ethanol (Cremophor $\mathrm{EL}^{\circledR}$ ) vehicle to improve solubility. Data supporting this dosage are discussed.

Preclinical trials established that the maximum tolerated dose (MTD) for ixabepilone was $10 \mathrm{mg} / \mathrm{kg}$ in mouse xenograft models [11]. The dose shown to give equivalent exposure in humans was $40 \mathrm{mg} / \mathrm{m}^{2}$. This dose also produced clinically relevant antitumor activity in patients [8].

Phase I trials in patients with solid tumors assessed a number of different dosing schedules of the Cremophorbased formulation [12]. In a study by Mani et al. [13], 40 or $50 \mathrm{mg} / \mathrm{m}^{2}$ dosed once every 3 weeks was recommended for phase II trials. Once-daily dosing for 3 days (MTD $8-10 \mathrm{mg} / \mathrm{m}^{2}$ ) [14] or 5 days (MTD $6 \mathrm{mg} / \mathrm{m}^{2}$ ) every 3 weeks [12] was assessed in two separate studies. More recently (2009), Awada and colleagues [15] assessed a weekly dosing schedule of MTD $25 \mathrm{mg} / \mathrm{m}^{2}$ as a 30-min infusion every week continuously or $20 \mathrm{mg} / \mathrm{m}^{2}$ as a 1 -h infusion for 3 weeks with a 1 -week break.

Phase II and phase III clinical trials in heavily pretreated patients with $\mathrm{MBC}$ generally utilized a dosing schedule of $40 \mathrm{mg} / \mathrm{m}^{2}$ once every 3 weeks. This regimen was effective and well tolerated. Table 1 summarizes the phase II clinical trials and dosing schedules that have been investigated (registrational and non-registrational trials included) [16-22]. Daily ixabepilone, administered at a dose of $8-10 \mathrm{mg} / \mathrm{m}^{2}$ for 3 days, did not demonstrate meaningful efficacy in patients with MBC previously treated with taxanes, although it was well tolerated [21]. However, in a phase II trial in patients with MBC who had not received prior taxane treatment, the $6 \mathrm{mg} / \mathrm{m}^{2}$ daily schedule (five consecutive days every 3 weeks) was well tolerated and demonstrated clinically meaningful efficacy $(57 \%$ had partial responses) [19]. Recently, Smith et al. [22] presented toxicity results from a phase II randomized trial comparing ixabepilone dosed once weekly (Arm 1: $16 \mathrm{mg} / \mathrm{m}^{2}$ over $1 \mathrm{~h}$ on Days 1,8 , and 15 of each 28 -day cycle) vs. every 3 weeks (Arm 2: $40 \mathrm{mg} / \mathrm{m}^{2}$ over 3 h on Day 1 of each 21-day cycle) in patients with MBC. Preliminary data showed that both dosing schedules had an acceptable safety profile; however, more adverse events (AEs) were reported in patients in Arm 2 compared with Arm 1 (grades 3-4 treatment-related AEs: $57 \%$ vs. $22 \%$; serious AEs: $36 \%$ vs. 28\%; grades 3-4 treatment-related neutropenia: $33 \%$ vs. $5 \%$, respectively). Other grades 3-4 treatment-related AEs occurring in $>5 \%$ of patients were reported more frequently in Arm 2 than in Arm 1 (fatigue: $16 \%$ vs. 5\%; neuropathy: $14 \%$ vs. $5 \%$; dehydration: $10 \%$ vs. $1 \%$; and vomiting: $6 \%$ vs. $0 \%$, respectively). More patients in Arm 2 discontinued the study due to treatment-related AEs (14\% vs. $7 \%)$.

\section{Doses and schedules in combination with other agents}

\section{Ixabepilone and capecitabine}

Synergistic effects between ixabepilone and capecitabine were demonstrated in pre-clinical studies [23]. A phase I/II trial assessed suitable treatment schedules for combination therapy of ixabepilone and capecitabine [24]. In the phase I, dose escalation study, patients received either a schedule A regimen (ixabepilone $40 \mathrm{mg} / \mathrm{m}^{2}$ intravenously on Day 1 plus capecitabine $1,650-2,000 \mathrm{mg} / \mathrm{m}^{2}$ on Days $1-14$ of a 3-week cycle) or a schedule $\mathrm{B}$ regimen (ixabepilone $8-10 \mathrm{mg} / \mathrm{m}^{2}$ on Days $1-3$ plus capecitabine $1,650 \mathrm{mg} / \mathrm{m}^{2}$ on Days 1-14 of a 3-week cycle). The MTD for schedule A was the $40 / 2,000 \mathrm{mg} / \mathrm{m}^{2}$ dose. During phase II of the study, this dosing schedule showed promising efficacy (objective response rate $[\mathrm{ORR}]=30 \%$ ) and was generally well tolerated, with grade $3 / 4$ events that included fatigue (34\%), handfoot syndrome (34\%), myalgia (23\%), nausea $(16 \%)$, peripheral neuropathy (19\%), and diarrhea/vomiting (10\%).

The large $(N=752)$ pivotal phase III trial utilized ixabepilone at $40 \mathrm{mg} / \mathrm{m}^{2}$ infused over $3 \mathrm{~h}$ on Day 1 of a 3-week cycle, in combination with oral capecitabine $2,000 \mathrm{mg} / \mathrm{m}^{2}$ on Days 1-14 of a 3-week cycle. Patients in the comparator arm received capecitabine $2,500 \mathrm{mg} / \mathrm{m}^{2}$ alone on the same dosing schedule [25]. The combination dose was well tolerated, with mostly grade $1 / 2$ AEs that were manageable and reversible. The most frequent grade 3/4 AEs in the combination group were peripheral sensory neuropathy, handfoot syndrome, fatigue, myalgia, asthenia, and diarrhea. The capecitabine group experienced grade 3 hand-foot syndrome and diarrhea at incidences similar to those for the combination arm. The ORR in the preliminary analysis was higher for the combination arm than for capecitabine alone (35\% vs. $14 \%$; odds ratio, $3.2 ; P<0.0001)$ [25]. This efficacy was confirmed in the final analysis, with response rates of 42 and $23 \%$ for the two arms, respectively [26]. Data showed that progression-free survival (PFS) was significantly higher for patients receiving ixabepilone plus capecitabine than for those receiving capecitabine alone 


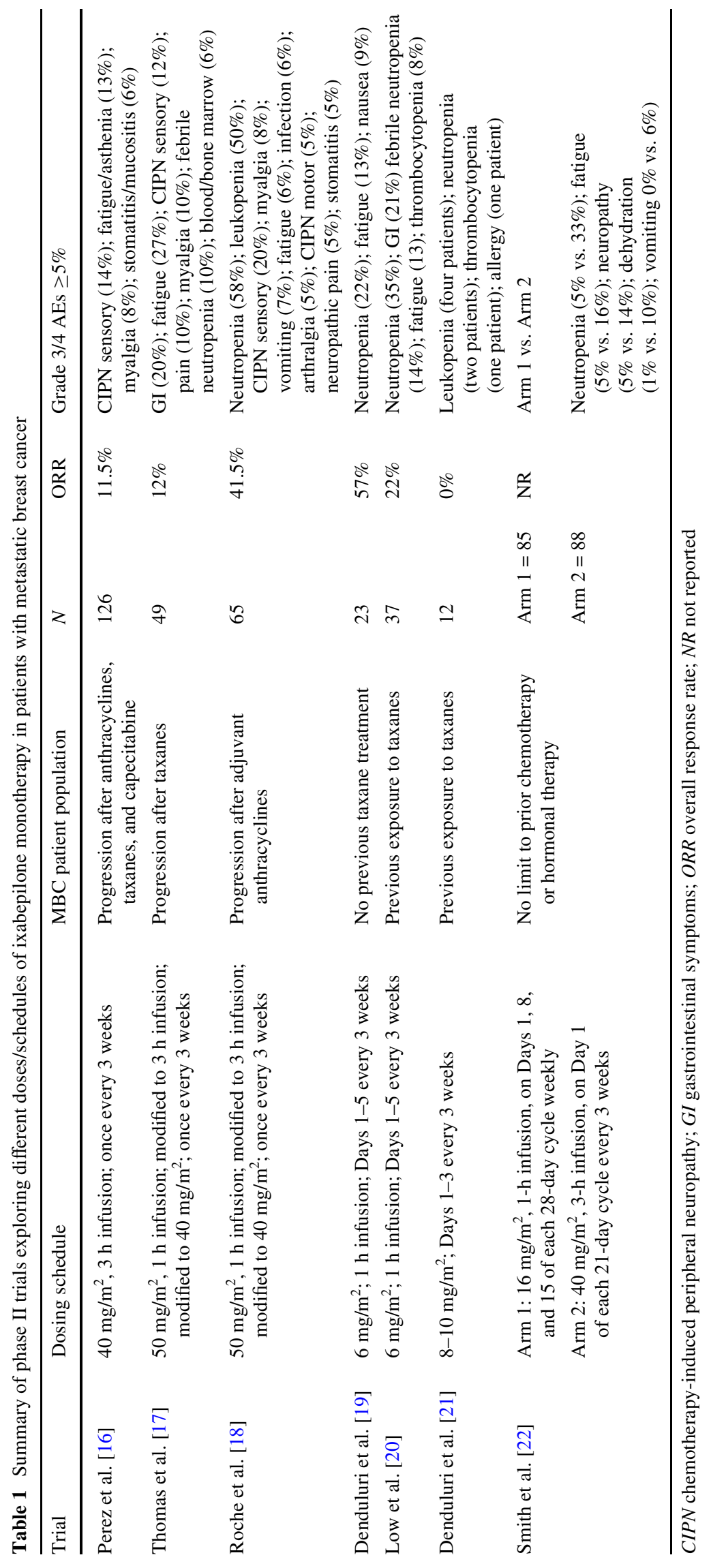


(5.3 vs. 3.8 months; HR 0.78; 95\% CI, 0.67-0.91; $P=0.0011$ ) [26]. The dose reduction rates for the combination arm were similar to those reported for capecitabine plus docetaxel [27]. Data from this phase III trial were further analyzed in order to assess the "trade-off" between toxicities and PFS ("Q-TWiST" analysis = quality-adjusted time without symptoms or toxicities). Results supported a positive risk/benefit to combination therapy with ixabepilone and capecitabine, compared with capecitabine alone (3.8-week improvement in quality-adjusted mean survival; $P=0.0227$ ) in patients with advanced or MBC refractory to anthracyclines and taxanes [28]. Further subanalysis (pooled patients with poor prognostic features: "triple-negative" phenotype or symptomatic KPS $70-80$ or postadjuvant rapid relapse) supported these results, affirming a positive risk/benefit ratio of ixabepalone plus capecitabine, compared with capecitabine alone. The greatest difference in quality-adjusted survival was found in the post-adjuvant rapid relapse subgroup $(45.6 \%$ vs. $36.0 \%$ for combination vs. monotherapy, respectively; $9.6 \%$ difference; $P=0.0007$ ) [29].

\section{Ixabepilone and bevacizumab}

There is preclinical evidence for synergy between ixabepilone and bevacizumab [30]. A recent (2009) randomized phase II trial investigated this combination as first-line therapy for MBC by comparing a weekly ixabepilone-based regimen $\left(16 \mathrm{mg} / \mathrm{m}^{2}\right.$ weekly for 3 weeks, every 4 weeks, plus bevacizumab $10 \mathrm{mg} / \mathrm{kg}$ every 2 weeks; Arm A) and an every-3-week ixabepilone-based regimen $\left(40 \mathrm{mg} / \mathrm{m}^{2}\right.$ every 3 weeks plus bevacizumab $15 \mathrm{mg} / \mathrm{kg}$ every 3 weeks; Arm B) to a combination of paclitaxel and bevacizumab $\left(90 \mathrm{mg} / \mathrm{m}^{2}\right.$ weekly, plus bevacizumab at the same dose and schedule as Arm A; Arm C) [31]. There was an automatic dose reduction of ixabepilone $40-32 \mathrm{mg} / \mathrm{m}^{2}$ after the fourth treatment cycle. The preliminary analysis revealed comparable response rates (Arm A, 50\% [34.9-65.1]; Arm B, 71\% [55.7-83.6]; and Arm C, 56\% [37.7-73.6]) and 24-week PFS rates (Arm A, 75\% [62.4-87.9]; Arm B, 86\% [75.796.4]; and Arm C, 94\% [85.4-100]) for all three arms, indicating that both schedules of ixabepilone are as efficacious as weekly paclitaxel when combined with bevacizumab. The most significant grade 3/4 AEs included peripheral neuropathy (Arm A, 18\%; Arm B, 22\%; and Arm C, 25\%) and neutropenia (Arm A, 11\%; Arm B, 55\%; and Arm C, $22 \%$ ). Febrile neutropenia rates were $<2 \%$ in all arms. The fact that rates of AEs were similar to those observed with ixabepilone monotherapy at these schedules suggests that ixabepilone does not exacerbate the $\mathrm{AE}$ profile of bevacizumab. Notably, although the trial investigated ixabepilone in combination with bevacizumab, this trial is the first to compare weekly ixabepilone to the approved every 3 -week schedule. The outcomes suggest that efficacy and tolerability of weekly ixabepilone might be comparable to the every 3 -week schedule, and evaluation of these two schedules (ixabepilone monotherapy) in MBC is currently underway (ClinicalTrials.gov identifier: NCT00593827).

Ixabepilone and lapatinib

The therapeutic potential of combining ixabepilone and lapatinib was recently (2009) evaluated in a preclinical study in breast cancer cell lines. Results showed that the combination of these two agents significantly reduced cell proliferation compared with the non-Her-2-amplified control $(P<0.001$ at $120 \mathrm{~h})$ [32]. Based on the favorable results of this study, a phase I dose escalation trial of ixabepilone $\left(32 \mathrm{mg} / \mathrm{m}^{2}\right.$ intravenous once every 3 weeks) in combination with lapatinib $(1,000 \mathrm{mg}$ orally once daily), with or without capecitabine $\left(1,650 \mathrm{mg} / \mathrm{m}^{2}\right.$ orally twice a day for 14 days), for up to 54 weeks depending on response, has been initiated in patients with Her-2 positive, taxane- and trastuzumab-resistant advanced breast cancer (NCT00634088). At the time of this publication, patient accrual is still underway; however, RECIST (response evaluation criteria in solid tumors) responses have been confirmed in two of the first three patients enrolled in this trial [32].

\section{Predicting response: gene expression patterns}

Recent studies have investigated the use of gene expression patterns to predict response to ixabepilone. Baselga et al. [33] evaluated the safety, efficacy, and genomic predictors of neoadjuvant ixabepilone therapy $\left(40 \mathrm{mg} / \mathrm{m}^{2}, 3\right.$-h infusion every 21 days, up to four cycles) in a single-arm, phase II study in patients with invasive breast cancer. Investigators identified estrogen receptor (ER) and microtubuleassociated protein tau as predictive markers for pathologic complete response to ixabepilone as neoadjuvant therapy (tau gene expression inversely correlated with ixabepilone sensitivity). Further, data from Horak et al. [34] indicated a higher $\beta$ III-tubulin expression in patients with "triple-negative" (negative or low expression of ER, PR, and HER2) breast cancer with basal-like tumors (breast cancer subtype defined by gene expression and protein expression profiles; often considered synonymous with triple-negative breast cancer). Investigators noted that $\beta$ III-tubulin overexpression might contribute to the aggressiveness of "triple-negative" breast cancer and that increased levels may be a predictor of response to treatment with ixabepilone. These studies indicate that the use of gene expression analysis prior to initiating ixabepilone therapy maybe be used to 
select patients who might derive clinical benefit from this treatment.

\section{Dose modifications reductions}

Cytotoxic chemotherapy requires balancing risk and benefit. Dose modification is used to manage the toxicities associated with therapy relative to the patient's ability to tolerate the therapeutic regimen. Dose modification to mitigate toxicity can be achieved either by reducing the dose administered, increasing/delaying the time between treatment periods, or altering the infusion time in order to maintain drug exposure but limit the peak plasma drug concentration often associated with toxic events.

\section{In the clinical setting}

Dose modifications of ixabepilone were necessary in many clinical trials to mitigate the AEs experienced by study participants or patients. Although $50 \mathrm{mg} / \mathrm{m}^{2}$ had been identified as the MTD in one phase I trial, the dose in two subsequent phase II trials was reduced from 50 to $40 \mathrm{mg} / \mathrm{m}^{2}$ to reduce the incidence of myelosuppression and mucositis. Additionally, in these studies, the 1-h infusion was lengthened to $3 \mathrm{~h}$ due to treatment-limiting neurotoxicity with the shorter infusion time [17, 18]. Data from these studies led to the use of a 3-h infusion of ixabepilone at 40 $\mathrm{mg} / \mathrm{m}^{2}$ in subsequent clinical trials and is the approved dosing as monotherapy and in combination with capecitabine $[12,18,25]$.

In the phase II registrational trial of ixabepilone monotherapy in MBC patients following a taxane, anthracycline, and capecitabine, dose reductions to 32 or $25 \mathrm{mg} / \mathrm{m}^{2}$ were made based on tolerability to ixabepilone in the previous cycle [16]. Seventy percent of patients received $\geq 90 \%$ of their planned relative dose intensity, and $80 \%$ of the cycles in the trial were administered at $40 \mathrm{mg} / \mathrm{m}^{2}$ as planned.

In the pivotal phase III ixabepilone/capecitabine combination trial, 51 and $45 \%$ of patients in the combination arm required dose reduction of ixabepilone and capecitabine, respectively, compared with dose reductions in $37 \%$ of patients in the single-agent capecitabine group [25]. The majority of patients received $\geq 70 \%$ of their planned relative dose intensity: in the combination group, 88 and $62 \%$ received $\geq 70 \%$ of their relative ixabepilone and capecitabine $\left(2,000 \mathrm{mg} / \mathrm{m}^{2}\right)$ dose intensity, respectively, compared with $82 \%$ in the capecitabine group $\left(2,500 \mathrm{mg} / \mathrm{m}^{2}\right)$.

In clinical practice

The main dose-limiting AEs in patients treated with ixabepilone are neutropenia and peripheral sensory neuropathy.
Both of the AEs are manageable, reversible, and responsive to dose reduction or delay [10]. However, patients with $\geq$ grade 2 neuropathy were excluded from the ixabepilone studies, and caution should be used when treating patients with diabetes mellitus or pre-existing peripheral neuropathy. In patients who have baseline neutrophil count $<1,500$ cells $/ \mathrm{mm}^{3}$, or baseline platelet count $<100,000$ cells $/ \mathrm{mm}^{3}$, ixabepilone is contraindicated.

Combination therapy with ixabepilone and capecitabine is contraindicated for patients whose levels of aspartate aminotransferase (AST) or alanine aminotransferase (ALT) exceed 2.5 times the upper limit of normal (ULN) or patients whose bilirubin exceeds ULN. Based on liver enzyme levels, patients may receive ixabepilone monotherapy at a reduced dose. However, the ixabepilone prescribing information provides specific guidelines for dose reduction or delay in several situations, including AEs, impaired hepatic function, and potential drug-drug interactions (Table 2) [10]. Doses for patients whose body surface area exceeds $2.2 \mathrm{~m}^{2}$ should be calculated based on $2.2 \mathrm{~m}^{2}$ [10]. In order to ensure that each patient is receiving the optimal dose, all patients should be routinely monitored for AEs that may signal that a dose reduction is necessary; i.e., regular complete blood counts, neurological exams, and liver function tests [10]. There is no antidote for ixabepilone overdose [10], and patients should be monitored and offered supportive care for any presenting clinical manifestations. Overdosage has been reported for one patient who received $100 \mathrm{mg} / \mathrm{m}^{2}$ (total $185 \mathrm{mg}$ ); however, the effects were minor (grade 1 fatigue and myalgia), and the patient made a full recovery [10].

\section{Drug interactions}

Ixabepilone is a weak inhibitor of human CYP3A4, but it is not expected to alter the plasma concentrations of other drugs [10]. Its main route of metabolism is via CYP3A4, and substances that inhibit CYP3A4 activity may decrease metabolism, thereby increasing plasma concentrations of ixabepilone. When ixabepilone is coadministered with strong inhibitors of CYP3A4, such as ketoconazole, itraconazole, ritonavir, amprenavir, indinavir, nelfinavir, delavirdine, and voriconazole, there is a significant increase in exposure to ixabepilone, and alternative therapeutic agents that do not inhibit CYP3A4 should be considered. In cases where coadministration of a strong CYP3A4 inhibitor cannot be avoided, a 50\% dose reduction of ixabepilone should be considered in order to adjust the ixabepilone area under the curve to that observed in the absence of concurrent CYP3A4 inhibitors, and patients should be monitored closely for acute toxicities [10]. 
Table 2 Recommended ixabepilone dose reductions and treatment discontinuations [10]
$A L T$ alanine aminotransferase, AST aspartate aminotransferase, $U L N$ upper limit of normal

a Toxicities graded in accordance with the National Cancer Institute (NCI) Common terminology criteria for adverse events (CTCAE v3.0)

${ }^{\mathrm{b}}$ Excludes patients whose total bilirubin is elevated due to Gilbert's disease

c Applies to ixabepilone monotherapy only. Ixabepilone and capecitabine combination therapy is contraindicated in this setting

\begin{tabular}{|c|c|}
\hline Issue & Recommendations \\
\hline \multicolumn{2}{|l|}{ Monotherapy OR combination therapy dose modifications } \\
\hline \multicolumn{2}{|l|}{ Non-hematologic adverse events ${ }^{\mathrm{a}}$} \\
\hline Grade 2 neuropathy lasting $\geq 7$ days & Decrease dose by $20 \%$ \\
\hline Grade 3 neuropathy lasting $<7$ days & Decrease dose by $20 \%$ \\
\hline $\begin{array}{l}\text { Grade } 2 \text { neuropathy lasting } \geq 7 \text { days, } \\
\text { or disabling neuropathy }\end{array}$ & Discontinue treatment \\
\hline Any grade 3 toxicity other than neuropathy & Decrease dose by $20 \%$ \\
\hline Transient grade 3 arthralgia/myalgia & No change in dose \\
\hline Transient grade 3 fatigue & No change in dose \\
\hline Grade 3 hand-foot syndrome & No change in dose \\
\hline Any grade 4 toxicity & Discontinue treatment \\
\hline \multicolumn{2}{|l|}{ Hematologic adverse events ${ }^{\mathrm{a}}$} \\
\hline Neutrophils $<500$ cells $/ \mathrm{mm}^{3}$ for $\geq 7$ days & Decrease dose by $20 \%$ \\
\hline Febrile neutropenia & Decrease dose by $20 \%$ \\
\hline Platelets $<25,000 / \mathrm{mm}^{3}$ & Decrease dose by $20 \%$ \\
\hline Platelets $<50,000 / \mathrm{mm}^{3}$ with bleeding & Decrease dose by $20 \%$ \\
\hline \multicolumn{2}{|l|}{ Potential drug interactions } \\
\hline Concomitant strong CYP3A4 inhibitor & Decrease dose to $20 \mathrm{mg} / \mathrm{m}^{2}$ \\
\hline \multicolumn{2}{|l|}{ Monotherapy dose modifications } \\
\hline \multicolumn{2}{|l|}{ Baseline hepatic impairment } \\
\hline AST and ALT $\leq 2.5$ and bilirubin $\leq 1 \times \mathrm{ULN}^{\mathrm{b}}$ & $\begin{array}{l}\text { No change in dose of monotherapy } \\
\text { or combination therapy }\end{array}$ \\
\hline AST and ALT $\leq 10$ and bilirubin $\leq 1.5 \times \mathrm{ULN}^{\mathrm{b}, \mathrm{c}}$ & Decrease monotherapy dose to $32 \mathrm{mg} / \mathrm{m}^{2}$ \\
\hline AST and ALT $\leq 10$ and bilirubin $>1.5-\leq 3 \times \mathrm{ULN}^{\mathrm{b}, \mathrm{c}}$ & Decrease monotherapy dose to $20-30 \mathrm{mg} / \mathrm{m}^{2}$ \\
\hline \multicolumn{2}{|l|}{ Combination therapy dose modifications } \\
\hline \multicolumn{2}{|l|}{ Baseline hepatic impairment } \\
\hline AST or ALT $>2.5$ or bilirubin $>1 \times \mathrm{ULN}^{\mathrm{b}}$ & Combination therapy is contraindicated \\
\hline
\end{tabular}

Alternatively, coadministration of substances that induce CYP3A4 activity, such as dexamethasone, phenytoin, carbamazepine, rifampin, and phenobarbital, may lead to subtherapeutic levels of ixabepilone, as they may increase ixabepilone metabolism, leading to a decrease in plasma concentration. In these patients, therapeutic agents with low enzyme induction potential for coadministration with ixabepilone may be considered. St. John's Wort should be avoided, as its effect on ixabepilone plasma concentrations is unpredictable [10].

\section{Other administration issues}

The Cremophor vehicle of ixabepilone can elicit hypersensitivity reactions (HSRs), but these can be prevented if patients receive oral $\mathrm{H}_{1}$ and $\mathrm{H}_{2}$ antihistamines approximately $1 \mathrm{~h}$ prior to infusion $[10,12]$. In contrast to standard formulations of the taxanes, corticosteroid premedication is not mandatory before ixabepilone infusion, unless the patient has experienced a previous hypersensitivity reaction to ixabepilone [10]. In patients who have a known history of severe hypersensitivity reactions to a drug formulated with Cremophor, ixabepilone is contraindicated.

The initial labeling in 2007 recommended that, after reconstitution, ixabepilone be further diluted using only Lactated Ringer's Injection, USP. This restriction was deemed necessary in order to maintain ixabepilone at a $\mathrm{pH}$ between 6.0 and 9.0, in order to maintain its stability. New labeling released in 2009 permits two alternative choices for infusion liquids, including PLASMA-LYTE A Injection, $\mathrm{pH} 7.4$, or $0.9 \%$ Sodium Chloride Injection, USP, with the $\mathrm{pH}$ adjusted to between 6.0 and 9.0 using two molar equivalents $(\mathrm{mEq})$ Sodium Bicarbonate Injection, USP. In order to obtain the desired $\mathrm{pH}, 2 \mathrm{ml}$ of an $8.4 \% \mathrm{w} / \mathrm{v}$ solution or $4 \mathrm{ml}$ of a $4.2 \%$ w/v solution of sodium bicarbonate must be added to each 250- or 500-ml bag of Sodium Chloride Injection before the addition of reconstituted ixabepilone.

\section{Summary and conclusions}

Clinically meaningful efficacy with ixabepilone is demonstrated in patients refractory to other chemotherapeutic 
options. Ixabepilone is generally well tolerated at the approved dose and administration schedule of $40 \mathrm{mg} / \mathrm{m}^{2}$ every 3 weeks. The most commonly observed dose-limiting AEs associated with ixabepilone are myelosuppression and peripheral neuropathy (primarily sensory). Dose modification including dose reduction and dosing schedule modification may be utilized to manage toxicities, but this must be based on careful hematologic, neurologic, and liver function monitoring. Other ixabepilone dose schedules are being evaluated to further improve risk/benefit, and weekly and daily schedules have shown useful efficacy and reasonable tolerability. Ixabepilone is also being evaluated in combination with other anticancer agents, in earlier breast cancer settings and in other indications.

Acknowledgments The author takes full responsibility for the content of this publication and confirms that it reflects her viewpoint and medical expertise. The author also wishes to acknowledge StemScientific, funded by Bristol-Myers Squibb, for providing writing and editing support. Neither Bristol-Myers Squibb nor StemScientific influenced the content of the manuscript, nor did the author receive financial compensation for authoring the manuscript.

\section{Conflicts of interest None.}

Open Access This article is distributed under the terms of the Creative Commons Attribution Noncommercial License which permits any noncommercial use, distribution, and reproduction in any medium, provided the original author(s) and source are credited.

\section{References}

1. Gerth K, Bedorf N, Hofle G, Irschik H, Reichenbach H (1996) Epothilons $\mathrm{A}$ and $\mathrm{B}$ : antifungal and cytotoxic compounds from Sorangium cellulosum (Myxobacteria). Production, physico-chemical and biological properties. J Antibiot (Tokyo) 49(6):560-563

2. Bollag DM, McQueney PA, Zhu J, Hensens O, Koupal L, Liesch J et al (1995) Epothilones, a new class of microtubule-stabilizing agents with a taxol-like mechanism of action. Cancer Res 55(11):2325-2333

3. Lee FY, Borzilleri R, Fairchild CR, Kamath A, Smykla R, Kramer R et al (2008) Preclinical discovery of ixabepilone, a highly active antineoplastic agent. Cancer Chemother Pharmacol 63(1):157-166

4. Giannakakou P, Gussio R, Nogales R, Downing KH, Zaharevitz D, Bollbuck B et al (2000) A common pharmacophore for epothilone and taxanes: molecular basis for drug resistance conferred by tubulin mutations in human cancer cells. Proc Natl Acad Sci 97(6):2904-2909

5. Jordan MA (2002) Mechanism of action of antitumor drugs that interact with microtubules and tubulin. Curr Med Chem Anticancer Agents 2(1):1-17

6. Wartmann M, Altmann KH (2002) The biology and medicinal chemistry of epothilones. Curr Med Chem Anticancer Agents 2(1):123-148

7. Dumontet C, Jordan MA, Lee FF (2009) Ixabepilone: targeting betaIII-tubulin expression in taxane-resistant malignancies. Mol Cancer Ther 8(1):17-25

8. Rivera E, Lee J, Davies A (2008) Clinical development of ixabepilone and other epothilones in patients with advanced solid tumors. Oncologist 13(12):1207-1223
9. Michaud LB (2009) The epothilones: how pharmacology relates to clinical utility. Ann Pharmacother 43(7):1294-1309

10. Myers Squibb Company (2009) IXEMPRA ${ }^{\circledR}$ (ixabepilone) prescribing information. Bristol-Myers Squibb Company, Princeton, NJ

11. Lee FY, Camuso A, Castaneda S, Fager K, Flefleh C, Inigo I et al (2006) Preclinical studies of ixabepilone (BMS-247550) demonstrate optimal antitumor activity against both chemotherapy-sensitive and -resistant tumor types. Proc Am Assoc Cancer Res 47:119 (Abstr 503)

12. Goodin S, Kane MP, Rubin EH (2004) Epothilones: mechanism of action and biologic activity. J Clin Oncol 22(10):2015-2025

13. Mani S, McDaid H, Hamilton A, Hochster H, Cohen MB, Khabelle D et al (2004) Phase I clinical and pharmacokinetic study of BMS-247550, a novel derivative of epothilone B, in solid tumors. Clin Cancer Res 10(4):1289-1298

14. Zhuang SH, Agrawal M, Edgerly M, Bakke S, Kotz H, Thambi P et al (2005) A phase I clinical trial of ixabepilone (BMS-247550), an epothilone B analog, administered intravenously on a daily schedule for 3 days. Cancer 103(9): 1932-1938

15. Awada A, Piccart MJ, Jones SF, Peck RA, Gil T, Lebwohl D et al (2009) Phase I dose escalation study of weekly ixabepilone, an epothilone analog, in patients with advanced solid tumors who have failed standard chemotherapy. Cancer Chemother Pharmacol 63(3):417-425

16. Perez EA, Lerzo G, Pivot X, Thomas E, Vahdat L, Bosserman L et al (2007) Efficacy and safety of ixabepilone (BMS-247550) in a phase II study of patients with advanced breast cancer resistant to an anthracycline, a taxane, and capecitabine. J Clin Oncol 25(23):3407-3414

17. Thomas E, Tabernero J, Fornier M, Conte P, Fumoleau P, Lluch A et al (2007) Phase II clinical trial of ixabepilone (BMS-247550), an epothilone B analog, in patients with taxane-resistant metastatic breast cancer. J Clin Oncol 25(23):3399-3406

18. Roche H, Yelle L, Cognetti F, Mauriac L, Bunnell C, Sparano J et al (2007) Phase II clinical trial of ixabepilone (BMS-247550), an epothilone B analog, as first-line therapy in patients with metastatic breast cancer previously treated with anthracycline chemotherapy. J Clin Oncol 25(23):3415-3420

19. Denduluri N, Low JA, Lee JJ, Berman AW, Walshe JM, Vatas U et al (2007) Phase II trial of ixabepilone, an epothilone B analog, in patients with metastatic breast cancer previously untreated with taxanes. J Clin Oncol 25(23):3421-3427

20. Low JA, Wedam SB, Lee JJ, Berman AW, Brufsky A, Yang SX et al (2005) Phase II clinical trial of ixabepilone (BMS-247550), an epothilone B analog, in metastatic and locally advanced breast cancer. J Clin Oncol 23(12):2726-2734

21. Denduluri N, Lee JJ, Walshe J, Berman AW, Vatas U, Chow CK et al (2007) Phase II trial of ixabepilone, an epothilone B analog, given daily for three days every three weeks, in metastatic breast cancer. Invest New Drugs 25(1):63-67

22. Smith JW, Vukelja SJ, Rabe AC, Pluenneke RE, WentworthHartung N, Benaderet LB et al (2009) Preliminary toxicity results of a phase II randomized trial of weekly or every-3-week ixabepilone in metastatic breast cancer (MBC). Cancer Res 69(24 Suppl):856s (Abstr 6099)

23. Lee FY, Camuso A, Castenada S, Flefleh C, Ingio I, Kan D et al (2006) Preclinical efficacy evaluation of ixabepilone (BMS247550) in combination with cetuximab or capecitabine in human colon and lung carcinoma xenografts. J Clin Oncol 24(18S):597s (Abstr 12017)

24. Bunnell C, Vahdat L, Schwartzberg L, Gralow J, Klimovsky J, Poulart V et al (2008) Phase I/II study of ixabepilone plus capecitabine in anthracycline-pretreated/resistant and taxane-resistant metastatic breast cancer. Clin Breast Cancer 8(3):234-241

25. Thomas ES, Gomez HL, Li RK, Chung HC, Fein LE, Chan VF et al (2007) Ixabepilone plus capecitabine for metastatic breast 
cancer progressing after anthracycline and taxane treatment. J Clin Oncol 25(33):5210-5217

26. Hortobagyi GN, Perez EA, Vrdoljak E, Medina C, Xu B, Conte P et al (2008) Analysis of overall survival (OS) among patients (pts) with metastatic breast cancer (MBC) receiving either ixabepilone (I) plus capecitabine (C) or $\mathrm{C}$ alone: results from two randomized phase III trials. Presented at the American society of clinical oncology breast cancer symposium, Washington, DC, 5-7 Sept (Abstr 186)

27. O’Shaughnessy J, Miles D, Vukelja S, Moiseyenko V, Ayoub JP, Cervantes $G$ et al (2002) Superior survival with capecitabine plus docetaxel combination therapy in anthracycline-pretreated patients with advanced breast cancer: phase III trial results. J Clin Oncol 20(12):2812-2823

28. Orsini L, Mukhopadhyay P, Peck R, Corey-Lisle P (2009) Quality adjusted time without symptoms or toxicities (Q-TWiST) of ixabepilone plus capecitabine versus capecitabine for metastatic breast cancer (MBC). Presented at the American society of clinical oncology breast cancer symposium, Orlando, FL, May 29-June 2 (Abstr 170)

29. Orsini L, Mukhopadhyay P, Peck R, Corey-Lisle P (2009) Quality adjusted time without symptoms or toxicities (Q-TWiST) of ixabepilone (Ixa) plus capecitabine (cape) versus capecitabine for metastatic breast cancer (MBC) patients with poor prognostic features (PPF). Cancer Res 69:782s (Abstr 5051)

30. Lee FY, Covello KL, Castaneda S, Hawken DR, Kan D, Lewin A et al (2008) Synergistic antitumor activity of ixabepilone (BMS247550) plus bevacizumab in multiple in vivo tumor models. Clin Cancer Res 14(24):8123-8131

31. Rugo HS, Campone M, Amadori D, Wardley A, Villa A, Conte PF et al (2009) Randomized phase II study of weekly versus every3 -week ixabepilone plus bevacizumab (ixa/bev) versus paclitaxel plus bev (pac/bev) as first-line therapy for metastatic breast cancer (MBC). J Clin Oncol 27(15S):47s (Abstr 1029)

32. Mainwaring PN, Nguyen T, Price G, Venter D (2009) Ixabepilone and lapatinib for HER2-positive advanced breast cancer: preclinical rationale and phase I trial. J Clin Oncol 27(15S):128s (Abstr 2582)

33. Baselga J, Zambetti M, Llombart-Cussac A, Manikhas G, Kubista E, Steger GG et al (2009) Phase II genomics study of ixabepilone as neoadjuvant treatment for breast cancer. J Clin Oncol 27(4):526534

34. Horak CE, Lee FY, Xu L, Galbraith S, Baselga J et al (2009) High $\beta$-III tubulin expression in triple-negative (TN) breast cancer (BC) subtype and correlation to ixabepilone response: a retrospective analysis. J Clin Oncol 27(15S):167s (Abstr 3587) 